\title{
Cheikh Anta Diop e as suas linhas extensivas: pensamento e crítica
}

\author{
Cheikh Anta Diop and his extensive lines: thought and criticism
}

\author{
Fernando Santos de Jesus ${ }^{*}$
}

Resumo: O pensamento do Senegalês Cheikh Anta Diop (1923-1986) tem ganhado bastante força no Brasil após maior abertura para os debates que campeiam os debates acerca das tensões e embates políticos em torno da questão racial. No ano de 2003 fora promulgada a lei 10.639/03, na qual altera a Lei de Diretrizes e Bases da Educação, de 1996, para a inclusão de disciplinas que abordem as histórias e as culturas do continente africano e seus descendentes na diáspora brasileira. Esse acontecimento possibilitou o amplo conhecimento de perspectivas teóricas que se balizam em Diop. Utilizamos referenciais teóricos que dialogam com essas posições, a fim de destacar que apesar da abertura política, os contrapontos estão presentes. Portanto, nosso objetivo é estimular uma reflexão teórica que conduza os nossos leitores a questionarem os arranjos epistemológicos que hoje se apresentam como ferramentas para disputas políticas no campo das relações étnico-raciais no Brasil.

Palavras-Chave: Epistemologia; Continente Africano; Contrapontos

\begin{abstract}
The thinking of the Senegalese Cheikh Anta Diop (1923-1986) has gained a lot of strength in Brazil after more openness to the debates that debate debates about the political tensions and clashes around the racial issue. Law No. 10.639 / 03, in which it amended the 1996 Law on the Guidelines and Bases of Education, was enacted in 2003 to include disciplines that address the histories and cultures of the African continent and its descendants in the Brazilian diaspora. This event made possible the broad knowledge of theoretical perspectives that are based on Diop. We use theoretical references that dialogue with these positions, in order to emphasize that despite political openness, counterpoints are present. Therefore, our objective is to stimulate a theoretical reflection that leads our readers to question the epistemological arrangements that today are presented as tools for political disputes in the field of ethnic-racial relations in Brazil.
\end{abstract}

Keywords: Epistemology; African Continent; Counterpoints

\section{Vida e obra}

O presente ensaio não visa se limitar a traçar a trajetória biográfica de Cheikh Anta Diop, se concentrando majoritariamente em algumas ideias contidas em suas obras e as críticas cabíveis. Por esse motivo, e entendendo a importância de localizar o leitor em relação a quem tenha sido o autor, dou início ao percurso através de uma breve explanação

\footnotetext{
* Doutorando em Educação pela Universidade Federal do Ceará-UFC. Bolsista do Conselho Nacional de Desenvolvimento Científico e Tecnológico-CNPq. E-mail: fernandosenzala@hotmail.com
} 
sobre o contexto em que este senegalês esteve inserido. Cabe salientar que não faremos uma análise sistemática em torno de cada obra, mas somente indicar as principais ideias defendidas por ele.

Cheikh Anta Diop nasceu no Senegal no ano de 1923 em uma família nobre e islamizada. Foi estudar na França e lá se forjou um intelectual de formação multidisciplinar, tendo adquirido conhecimentos de Física, Química, Antropologia, Filosofia, História e Sociologia. Neste mesmo país, Diop teve a sua tese de doutorado rejeitada no ano de 1954 ao defender a afirmação de que o antigo Egito era negro e que o continente africano possuía uma identidade cultural comum, que se comprovava por meio de um parentesco linguístico que se aglutina através da migração de povos negros dentro do próprio continente.

Diop encontrou muitas dificuldades e entraves no mundo acadêmico, visto que estamos falando do ano de 1954, período de grande repressão às populações negras ao longo do mundo. Nesse sentido, não podemos deixar de mencionar que a ambiência parecia desfavorável ao arvorecer de novas configurações epistemológicas que, posteriormente, transformaria os espaços educativos e inflamaria, ainda mais, a “consciência racial” em nações as quais a negação dos direitos civis para os negros matizava a estrada das populações brancas.

O legado filosófico grego enquanto berço do pensamento ocidental continuava intrépido - como ainda hoje é o modelo dominante - e ideias que ousavam questionar o protagonismo do pensamento europeu tenderiam ao ostracismo. Desse modo, é importante salientar que Diop não estava sozinho, outros brilhantes pensadores também escreveram teses as quais questionavam o modelo ocidental de organizar o mundo, mas também foram invisibilizados pela indústria do imaginário eurocêntrico, que selecionava em que base epistemológica os países colonizados deveriam se balizar. Diop está inscrito em um contexto que deleita um rol de grandes pensadores negros, dos quais podemos dar destaque ao martinicano Frantz Fanon (1925-1961), o brasileiro Guerreiro Ramos (19151982), o estadunidense William Edward Du Bois (1868-1963), dentre outros.

Os entraves e investidas racistas para inviabilizar uma insurreição negra no pensamento, não foram suficientes para que Diop deixasse de pesquisar e documentar seus estudos, seu legado está materializado nos livros (títulos originais em francês): "Nations nègres et culture: de l'Antiquité nègre égyptienne aux problèmes culturels de l'Afrique noire d'aujourd'hui”, “L’unité culturelle de l'Afrique noire”, “L’Antiquité africaine par l’image", "L’Afrique noire précoloniale. Étude comparée des systèmes politiques et sociaux de l'Europe et de l'Afrique noire de l'Antiquité à la formation des États modernes”, "Les fondements culturels, techniques et industriels d'un futur État fédéral d'Afrique noire", "Antériorité des civilisations nègres: mythe ou vérité historique ?", "Parenté génétique de l'égyptien pharaonique et des langues négro-africaines", "Civilisation ou barbárie", 
"Nouvelles recherches sur l'égyptien ancien et les langues africaines modernes" (publicado postumamente).

Estas obras são escritas em um grande período de tempo, que se estende até um pouco antes de sua morte, no ano de 1986. Fica evidente que Diop atravessou um grande período de acontecimentos históricos do século $\mathrm{XX}$, influenciando e sendo influenciado por gerações de pesquisadores e ativistas que se inclinaram a (re)contar a história do continente africano.

\section{Pensamento e projeto político}

Para que o projeto de "unidade cultural" africana não fosse algo inócuo e sem virtualidade prática, Diop se inclinou em atacar o cerne do pensamento ocidental, afirmando que os povos originários da terra eram negros. Segundo ele, os primeiros habitantes do planeta não teriam como nascer em outro lugar senão no continente africano, e suas características físicas não poderiam estar desajustadas das condições climáticas. Por esse motivo, esses seres humanos eram negros. Essa premissa básica, afirma Diop, se confirma pelas condições geográficas do continente, que possibilita abundância de recursos naturais indispensáveis para a vida.

A partir dessa concepção, Diop passa a traçar o caminho epistemológico tendo como princípio norteador as características fundamentais de dois berços da humanidade que ele descreve como: Meridional Melanodérmico e Setentrional Leucodérmico. O primeiro é referente ao berço da humanidade, baseia-se nas condições de vida encontradas no continente africano e o segundo é atinente à porção ocidental. De acordo com Diop, seria possível conjecturar em que bases comportamentais estariam suscetíveis os povos provindos de cada berço, tendo como elemento de análise a reconstrução das organizações políticas e sociais, de acordo com acesso aos recursos naturais e o clima de cada região. Diop afirma que:

$\mathrm{O}$ berço meridional confinado ao continente africano em particular caracteriza-se pela família matriarcal, pela criação do Estado-territorial, por oposição à Cidade-Estado ariana, pela emancipação da mulher na vida doméstica, pela xenofilia, pelo cosmopolitismo, por uma espécie de coletivismo social tendo como corolário a quietude, chegando até à despreocupação em relação ao futuro, por uma solidariedade material de direito para cada indivíduo, e que faz com que a miséria material ou moral seja desconhecida até aos nossos dias; existem pessoas pobres, mas ninguém se sente só, ninguém está angustiado. No domínio moral, um ideal de paz, justiça, bondade, de um otimismo que elimina qualquer noção de culpa ou de pecado original nas criações religiosas ou metafisicas. O gênero literário predileto é o narrativo - o romance, o conto, a fábula e a comédia. 
O berço nórdico confinado à Grécia e a Roma caracteriza-se pela família patriarcal, pela Cidade-Estado (entre duas cidades existia, afirma Fustel de Coulanges, algo de mais intransponível do que uma montanha) percebe-se facilmente que é no contato com o mundo meridional que os nórdicos expandiram a sua concepção estatal para se erguer ao nível da ideia de um Estado territorial e de um império. O caráter particular destas CidadesEstado, no exterior quais se era um fora da lei, desenvolveu o patriotismo no seu interior, bem como a xenofobia. O individualismo, a solidão moral e material, a repugnância pela existência, toda a matéria da literatura moderna que, mesmo sob os seus aspectos filosóficos, não representa outra coisa senão a expressão da tragédia de uma vida, cujo estilo remonta aos antepassados, constituem o apanágio deste berço.

Um ideal de guerra, de violência, de crime, de conquistas, herdado da vida nómada, tendo por corolário um sentimento de culpabilidade ou de pecado original que representa o fundamento dos sistemas religiosos ou metafísicos pessimistas são o apanágio do mesmo ${ }^{1}$.

Estas possibilidades, segundo Diop, fundamentariam os pilares da cultura ocidental contemporânea, que através de intensa e constante investida contra o continente africano, teria se tornado dominante. De acordo com o antropólogo Carlos Moore ${ }^{2}$, em leitura de Diop, o mundo ocidental teria erguido seu império através da intensificação de uma ordem sistêmica de profunda realidade histórica e alcance geográfico, na organização do pensamento em torno dos elementos visíveis de diferenciação entre os indivíduos, criando uma hierarquia baseada no fenótipo.

A identidade cultural africana, possibilitada pelo fio condutor da memória e da espiritualidade, teria papel central na resistência das populações negras africanas em relação a força da dominação colonial. Corolário, a cultura negra se faz predominante até no mundo ocidental, isto é, ainda que a dominância na gestão dos recursos econômicos seja europeia, através da massificação do ethos europeu, os legados culturais africanos estão entrelaçados por dentro dos diversos modos de conceber os elementos éticos, políticos, metafísicos, estéticos e lógicos que permeiam as sociedades contemporâneas.

Essa ocorrência, segundo Diop, se deve ao fato de o berço da civilização europeia, a Grécia, ter sido forjado a partir do contato com os egípcios e desses encontros terem retirado importantes "nutrientes" epistêmicos para a organização do logos grego. A localização geográfica e a intensa migração de povos na antiguidade permitiriam, portanto, afirmar sobre a impossibilidade de um “milagre grego", ou seja, de um

\footnotetext{
${ }^{1}$ DIOP, A unidade Cultural da África Negra: Esferas do Patriarcado e do Matriarcado na Antiguidade Clássica, p. 173.

${ }^{2}$ MOORE, A Humanidade Contra si Mesma: Para uma Nova Interpretação Epistemológica do Racismo e de seu Papel Estruturante na História e no Mundo Contemporâneo, 2011.
} 
desenvolvimento filosófico apartado dos acontecimentos produzidos concomitantemente em outros lugares.

Para atestar comprovação dessa premissa, Diop se faz valer de relatos de filósofos e historiadores gregos viventes na antiguidade. Importantes figuras como: Heródoto, Diodoro da Sicília, Sólon o legislador de Atenas, dentre outros. Essas passagens são constantemente evocadas nas obras do senegalês, na tentativa de "descortinar" a visão dos antigos sobre o continente africano.

These three examples reveal that Herodotus was not a passive reporter of incredible tales and rubbish, "a liar". On the contrary, he was quite scrupulous, objective, scientific for his time. Why should one seek to discredit such a historian, to make him seem naive? Why "refabricate" history despite his explicit evidence?

Undoubtedly the basic reason for this that Herodotus, after relating his eyewitness account informing us that the Egyptians were Blacks, the demonstrated, whit rare honest (for a Greek), that Greece borrowed from Egypt all the elements of her civilization. Moreover, archeological discoveries continually justify Herodotus against his detractors. Thus, Christiane Desroches-Noblecourt writes about recent excavations in Tanis: "Herodotus had seen the outer buildings of these sepulchers and had described them. [this was the Labyrinth discussed above.] Pierre Montet has just proved once again that "The Father of History did not lie" 3.

Nesta afirmação reside um elemento central da obra de Diop, a de que o Egito era uma nação negra, e não um estado que representava uma África branca, conforme, segundo ele, o pensamento hegemônico europeu buscou enquadrá-los. Essa posição política está alicerçada na ideia geográfica de pertencimento ao berço Meridional Melanodérmico (já mencionado), e na ideia de auto declaração, a partir de uma identidade unificada no comum pertencer construído pela confluência de culturas negras, para o que Théophile Obenga ${ }^{4}$ classifica como "Memória mais arquivada do mundo".

No Egito, foi possível conceber diferentes fontes históricas; narrativas, grafias e fósseis arqueológicos, que atestam para a presença de povos vindos de outras regiões do continente africano, de troncos linguísticos e culturais diversos, como Bantos e Yorubás. Daí proviria a suspeita levantada por Théophile Obenga, de que o Egito seria a civilização responsável por guardar “a memória dos povos”. Para este autor, seguindo as pistas deixadas por Cheikh Anta Diop, o filósofo mais cobiçado pelo ocidente, Platão, e seus antecessores - Pré-Socráticos - teriam estudado no Egito e forjado todas as suas filosofias a partir de lá.

\footnotetext{
${ }^{3}$ DIOP, The African Origin of Civilization: Myth or Reality, p.4.

${ }^{4}$ OBENGA, O Egipto da Obra de Platão, 2014.
} 
Talvez o linguista e filósofo africano esteja exagerando ao afirmar que toda a filosofia desses pensadores teria sido forjada a partir do Egito, até mesmo porque cada um deles já desenvolviam seus pensamentos antes de passar por um período de tempo naquele continente, e, posteriormente, regressaram aos seus lugares de origem, onde continuaram seus estudos. Além desse fato, é importante entender que, segundo o próprio autor, o Egito seria um arquivo da memória dos povos, e para lá não confluíram somente gregos e outros africanos.

Apesar desse exagero, que pode estar na base do pensamento de Diop, estendido pelos seus seguidores, é possível confirmar a anterioridade de textos filosóficos já escritos a partir do continente africano, e que eles possivelmente influenciaram os modos de pensar dos gregos. Portanto, segundo Diop, o discurso que afirma que a filosofia seria fruto de um "milagre grego", não condiz com um modo sério de produzir e (re)contar a história da filosofia. É buscando desvelar um caráter falseador de uma ordem sistêmica antinegra, que Diop conjectura que os elementos culturais do mundo ocidental, e árabe, só ganharam forma por meio da influência africana, ele afirma que:

The anciet egyptians were Negroes. The moral fruit of their civilization is to be counted among the assets of the Black world. Instead of presenting itself to history as an insolvent debtor, that Black world is the very intiator of the "western" civilization flaunted before our eyes today. Pythagorean mathematics, the theory of the four elements of the Thales of Miletus, Epicurean materialism, Platonic idealism, Judaism, islam and modern science are rooted in Egyptian cosmogony and science. One needs only to meditate on Osiris, the redeemergod, who sacrifices himself, dies, and is resurrected to save mankind, a figure essentially identifiable whit Christ ${ }^{5}$.

De acordo com essa posição, Diop deixa aberto o caminho para a interpretação de que toda cultura ocidental não passaria de um desdobramento de conhecimentos anteriormente lançados pelos africanos, organizados a partir do Egito. Essa é uma afirmação bastante delicada e polêmica, já que Diop também não analisa outras possibilidades existenciais e suas influências culturais deixadas e/ou herdadas no contato entre povos. Isto é, Diop não lança uma sistematização analítica acerca dos povos orientais, sob a justificativa de falta de documentos que permitam (re)fazer um percurso de (re)construção de possibilidades vivenciais sobre aqueles povos.

Entretanto, Carlos Moore tece considerações a partir de possíveis estudos mais recentes (ele não cita que estudos são estes) que talvez permitem conjecturar acerca das populações asiáticas. Perseguindo as inquietações de Diop, Moore buscou demonstrar um caminho no qual fosse possível incluir o continente asiático no rol dos lugares onde a presença humana fosse posterior ao continente africano.

${ }^{5}$ DIOP, The African Origin of Civilization: Myth or Reality, p. xiv. 
As pesquisas mais recentes na esfera da biologia genética coincidem com as provas paleoantropológicas: os seres humanos modernos que saíram do continente africano entre 50 e 80 mil anos atrás, povoando todo o planeta, tinham pele negra e ostentavam as feições apresentadas até hoje pelos diversos povos que residem nesse continente (exceto a textura dos cabelos, que teriam sido lisos até recentemente, como é o caso dos povos negros da Índia e da Austrália). Um mecanismo de clareamento da pele (o gene SLC24A5) teria sido fixado pela seleção natural 18 mil anos atrás, provocando o surgimento de dois novos povos fenotípicos (raças): os protoeuropeus brancos e os protoasiáticos amarelos. A partir desse momento, essas populações continuaram diferençando-se fenotipicamente para, por fim, constituir as branco-europeias e amarelo-asiáticas da atualidade 6 .

Diop também lança mão de uma instigante provocação que desemboca na anterioridade dos negros na terra, afigurando novos contornos fenotípicos de acordo com a conjugação do clima aos elementos naturais disponíveis. De acordo com o autor, a lógica pode se manter inalterada se compararmos os traços fenotípicos entre negros e asiáticos, chegando à conclusão de que as características comuns são fruto da herança deixada pelos negros africanos que migraram para aquelas regiões.

The yellow race as well was probably the result of cross breeding between Blacks and Whites at a very ancient time in the history of mankind. In fact, the yellow peoples have the pigmentation of the mixed breeds, so much so that comparative biochemical analysis would be unable to reveal great difference in the quantity of melanin. No systematic study of the blood groups in mixed breeds has made been made to date. If would have permitted interesting comparison with those of the yellow race.

The ethnic features of yellow people, lips nose, prognathism, are those of the mixed breed. Their facies (high cheekbones, puffed eyelids, Mongolian puckers, slant eyes, depression at the bridge of the nose) could merely result from the effect of thousands of years in a climate that blows cold winds on the face. The crispation of the face as a result of the wind would suffice to explain the prominent cheekbones and puffed eyelids, which form two correlative ethnic traits. Beating against the face in cold weather, the wind can escape through the corner of the eye only by following an oblique upward movement, after the molecules of air have been warmed. In the long run, this mechanical force could produce a deformation of the eye in the same direction. Such an action by the climate could be even stronger on

\footnotetext{
${ }^{6}$ MOORE, A Humanidade Contra si Mesma: Para uma Nova Interpretação Epistemológica do Racismo e de seu Papel Estruturante na História e no Mundo Contemporâneo, p. 10.
} 
a young organism like that of a child. This explanation obviously assumes the hereditary of acquired characteristics. It is known, moreover, that these features, called Mongolian, change from northern to southern Asia, following to some extent a climate curve. And it has been observed that, wherever there are yellow-skinned peoples, one still find smell pockets of Black and Whites who seem to be residual elements of the race. This is the case throughout southeast Asia: the Mois in the mountains of Viet-Nam where, in addition, it is curious to encounter such names as Kha, Thai, and Cham; the Negritos and Ainus in Japan, etc. Acoording to a Japanese proverb: "For a Samurai to be brave, he must have bit of Black blood". Chinese chronicles report that Negro empire existed in the south of China at the dawn of that country's history. Proto-Aryan + Proto-Dravidian + Cold Climate $=$ Yellow ${ }^{7}$.

Essa afirmação segue como nota explicativa, que tem a pretensão de traçar linhas extensivas, possibilidades de estudos futuros. Nesse sentido, Diop se concentra em afirmar que todas as variações fenotípicas das populações humanas descendem de um ancestral comum, negro, nascido no continente africano.

The triumph of the monogenetic thesis of humanity (Leakey), even at the stage of "Homo Sapiens-Sapiens", compels one to admit that all races descended from the Black race, according to a filiation process that science will one day explain ${ }^{8}$.

Segundo Diop, esse seria um conhecimento básico e indispensável para afirmar que as maiores realizações da humanidade proviriam dos africanos. Leva-se em consideração o princípio educativo básico, que segundo Bergson ${ }^{9}$, se baseia na conservação das experiências positivas que são repassadas para as gerações posteriores, no intuito de minimizar os esforços em torno da construção de saberes indispensáveis para tornar a vida mais agradável e, por conseguinte, mais confortável. De acordo com essa possibilidade, os africanos que migraram para outros continentes, somente obtiveram êxito porque, já em seu continente, se educaram e desenvolveram as tecnologias que permitiriam a invenção de utensílios indispensáveis para a sobrevivência.

Segundo Diop, pode-se afirmar que os primeiros seres humanos, os negros africanos, desenvolviam pensamento filosófico e produziam ciência, além do fato de que estes conhecimentos atravessaram continentes, permitindo que os brancos - segundo ele uma variação fenotípica dos negros, devido condições climáticas - pudessem herdar essas realizações dos seus ancestrais negros.

\footnotetext{
${ }^{7}$ DIOP, The African Origin of Civilization: Myth or Reality, p. 280-281.

${ }^{8}$ Ibidem, p. xv.

${ }^{9}$ BERGSON, A Evolução Criadora, 2014.
} 
Todas as invenções mecânicas atribuídas a Arquimedes apresentam um caráter duvidoso; estas existiam no Egito milénios antes do seu nascimento. Os construtores das pirâmides do antigo império conhecem o princípio da alavanca; recorriam a este de modo diversificado para erguer toneladas de pedras até o topo das pirâmides em construção. Neste sentido, é impossível utilizar tal instrumentos sem associar de imediato a relação das massas e das distâncias sem teorizar. Arquimedes teria descoberto o parafuso sem fim que está na origem de um progresso mecânico considerável. Porém, Diodoro da Sicília é categórico, Arquimedes só poderia ter levado a cabo esta invenção após a sua viagem para o Egito, onde o parafuso hidráulico já era utilizado e servia para bombear a água. Isto afigura-se de tal modo evidente que é hoje geralmente aceite o fato de Arquimedes ter, no máximo, adaptado uma invenção egípcia ${ }^{10}$.

Ainda que Cheikh Anta Diop não tivesse dimensão da popularidade que esses estudos pudessem assumir, suas teorias ganharam forças interpretativas que geraram agenciamentos políticos que se tonificam a partir das décadas de 1960 e 1970, com a intensificação da afirmação da identidade negra nos Estados Unidos (através da conquista pelos direitos civis), nas lutas de libertação dos países africanos em face do poder colonial e com as (re)organizações de movimentos negros pelo mundo, orientados por ideologias Pan-africanistas que apresentavam alternativas diferentes das bases marxistas as quais os movimentos anteriores se balizavam.

Portanto, Cheikh Anta Diop teve o mérito e a coragem de apresentar ao mundo da ciência e do pensamento filosófico, novas perspectivas que transgrediam as fronteiras quase intransponíveis do chamado “eurocentrismo". Sua intenção era tonificar o sentimento de solidariedade das populações negras ao longo do mundo, tornando possível a edificação de um grande projeto de estado unificado africano, forte e desenvolvido, apartado da dependência econômica dos países industrializados e despido das influências epistemológicas ocidentais.

\section{Linhas extensivas a críticas ao pensamento afrocêntrico}

Uma das linhas interpretativas de reordenamento do pensamento de Cheikh Anta Diop se apresenta na proposta epistemológica cunhada pela Afrocentricidade, que tem como seu expoente máximo o afro-americano, professor doutor Molefi Kate Asante Arthur Lee Smith Jr. (1942), professor da universidade de Temple, nos Estados Unidos da

\footnotetext{
${ }^{10}$ DIOP, A unidade Cultural da África Negra: Esferas do Patriarcado e do Matriarcado na Antiguidade Clássica, p.
} 173. 
América. Salientamos que essa escola de pensamento agrega outros intelectuais que referendam os estudos africanos a partir dos EUA, se expandindo para outros continentes e contando com a cooperação de acadêmicos, atores de movimentos sociais e políticos.

Resumidamente, o princípio direcionador da Afrocentricidade se dá pelo questionamento: o que seria do mundo sem a presença das populações brancas? Segundo eles, as bases dos problemas sociais encontrados ao redor do mundo, se devem à cobiça e ao desejo de dominação das populações brancas ocidentais, que herdaram e desenvolveram os princípios comportamentais de seus antepassados brancos, viventes do berço Setentrional Leucodérmico. Para aqueles que seguem essa perspectiva, o sentimento de pertença a ancestralidade africana deve ser o centro de suas decisões, numa conjugação geográfica que estaria para além do continente africano, ou seja, os negros da diáspora deveriam conciliar a identidade negra a partir da premissa de que são todos africanos, independente da porção de mundo em que se encontram, e assim potencializar uma agenda negra unificada.

Essas perspectivas são amplamente discutíveis e questionadas por pensadores de várias origens étnicas, raciais e nacionais. Faremos uma breve localização da possível crítica a essa tendência de pensamento, utilizando o filósofo camaronês Achille Mbembe (1959). Tenho como justificativa de escolha, o fato de se tratar de um pensador negro e do continente africano, evitando qualquer bipolarização racial, na compreensão de que as teorias afrocêntricas não são consensuais entre a intelectualidade negra, bem como não são totalmente rejeitadas pela intelectualidade branca.

De acordo com o traçado crítico de $\mathrm{Mbembe}^{11}$, as "formas de auto-inscrição" daqueles que defendem uma identidade negra unificada - a partir do sentimento de pertença africano -, se alicerçam em uma corrente nativista que é baseada no princípio racial e particularista como meio de afirmação da diferença, se opondo a universalidade do conceito de raça (humana). Para o autor, existem outras correntes, como o Marxismo, que se baseia na narrativa revolucionária, na qual exerce um poder de mando centralizando os agenciamentos políticos em torno dos partidos políticos de esquerda. Desse modo, o que se articula por fora do crivo partidário correria o risco de se aproximar a oposição e ser combatida, estaria atrelado a um cunho "conservador".

A segunda corrente apresentada não constitui fruto para aprofundamento em nosso debate, já que Diop, e os que se articularam em torno de suas linhas extensivas, podem ser classificados por Mbembe enquanto nativistas. Nesse quadro, "estaria construída uma identidade forjada a partir da "vitimização", já que haveria um projeto político frustrado por forças exteriores que frearam as formas de autogestão dos povos africanos” ${ }^{12}$.

\footnotetext{
${ }^{11}$ MBEMBE, O Egipto da Obra de Platão, 2001.

${ }^{12}$ Segundo Mbembe, "Por trás do sonho da emancipação política e da retórica da autonomia, uma perversa operação foi estabelecida, cujo resultado apenas fortaleceu o ressentimento africano e sua neurose de vitimização”. Ver MBEMBE, As Formas Africanas de Auto-Inscrição, p. 186.
} 
O perigo dessas afirmações reside no fato de que se cria um devir africano aprisionado, com força de realização adiada, já que os agenciamentos políticos das populações negras deveriam estar conciliados na noção de um povo unificado, que necessitariam resgatar uma identidade comum, perdida no tempo e no espaço, uma vez que as forças neutralizantes do eurocentrismo não permitiriam a continuidade de decisões autônomas, pois o esmagamento do racismo criaria um déficit negro em relação a si mesmo. Desse modo, somente o resgate ancestral mais pré-colonial possível, seria capaz de reorganizar o jogo político e devolver a força de movimentação para as pessoas negras, que passariam a valorizar somente aquilo que fora construído genuinamente por negros não afetados pelo poder colonial.

Segundo Mbembe, a busca “obsessiva” em demonstrar grandes realizações filosóficas e científicas da antiguidade, só reforçam o aprisionamento existencial dos grupos que se orientam pelas teses nativistas. Para ele, a necessidade de se auto referendar atesta para um discurso de autoctonia que assume a radicalidade da diferença, e a impossibilidade (pelo menos discursiva) de retorno a universalidade (Humanidade). Seguindo as críticas de Mbembe, trazemos um exemplo para ilustrar a possibilidade da existência sobre a necessidade de comprovar que a filosofia ocidental se fez valer do contato com o continente africano para existir. Vejamos no exemplo retirado do texto de Obenga:

O Egito desempenhou um papel significativo no pensamento de Platão: perto de $42 \%$ dos seus discursos concernem directa e amplamente ao Egito, país da mais alta Antiguidade, berço da escrita e das ciências, modelo de organização artística, intelectual e pedagógica. E Plutarco, desde a própria antiguidade, dedicou-se a ler as leis, a República, o Banquete e, sobretudo, o Timeu e Fedra, precisando aquilo que, segundo ele, era devido ao Egito ${ }^{13}$.

A partir dessa afirmação de Obenga, reside um estranho fato, o da auto-referência de grandeza que se faz sobre o Egito que, no entanto, necessitaria centralizar a figura de um ocidental, nesse caso Platão, para atestar a legitimidade de uma filosofia genuinamente africana, mais especificamente no Egípcia. Ou seja, para tornar a filosofia africana potente fora preciso o crivo de Platão como testemunho de que aquele lugar seria o nascedouro da filosofia e da ciência? Parece um tanto contraditório tal afirmação, e essa realmente é uma indagação que enfraquece o argumento apresentado pelas teses nativistas.

Os intérpretes, assim como os analistas africanos, têm usado categorias e sistemas conceituais que dependem de uma ordem epistemológica ocidental. Mesmo nas descrições mais explicitamente 'afrocêntricas', os

${ }^{13}$ OBENGA, O Egipto da Obra de Platão, p. 214. 
modelos de análise, explicitamente ou de forma implícita, consciente ou inconscientemente, se referem à mesma ordem ${ }^{14}$.

De acordo com essa afirmação, existe um axioma conceitual, tornando as explicações que atestam para uma autoctonia filosófica africana, algo circular, que para tornar possível sua (re)leitura, ou interpretação, necessita recair em vários pontos sistematizados pelos supostos algozes, os ocidentais. Para Muniz Sodré, o fato de afirmar que é possível produzir conhecimento no seio das diversas populações africanas não altera o quadro de interdependência entre as culturas globais, e a tendência de centralizar os acontecimentos humanos no continente da África, tornando todo o resto desdobramento deste fato, seria um risco assumido por pensadores afro-americanos desde a década de 1970.

A novidade é também possibilitada por um discurso que remonta ao início dos anos setenta nos Estados Unidos quando, junto com movimentos políticos e culturais de valorização do negro, produziu-se uma conjuntura acadêmica afrocêntrica. Para o Scholar afrocentrado, isto é, aquele que segue a linha do antropólogo senegalês Cheikh Anta Diop, a cultura europeia provém do Egito, por sua vez parte da África (...).A interpretação de Diop tem, antes de mais nada, o mérito de contraditar toda uma tradição acadêmica que, desde o século dezenove, tentava "embranquecer" os egípcios para explicar, segundo a conveniência euro-racista, fatos civilizatórios altamente valorizáveis, como a invenção das pirâmides, dos hieróglifos, dos conhecimentos astronômicos e arquitetônicos, etc. chegando-se mesmo a dizer que os egípcios eram "membros escuros da Grande Raça Branca” (...).Deduzir daí, entretanto, uma teoria geral da "africanidade" é particularmente problemático, quando primeiro se considera a evidência geo-histórica de que muitos dos povos africanos provieram também de regiões mesopotâmicas e asiáticas do leste do rio Nilo. Depois, sustentar, como faz Diop, que o Egito faraônico foi o centro irradiador de todo o processo civilizatório europeu graças à influência egípcia sobre os gregos, é no mínimo um risco acadêmico, compreensível apenas no quadro da luta ideológica entre a antropologia afrocêntrica e o difusionismo racista dos euroamericanos ${ }^{15}$.

Vemos que a questão está posta em um patamar muito mais localizado em uma luta ideológica, do que na construção de conhecimentos que articule questões diversas, onde se concorde que no continente africano "nem tudo são flores". O que se deve evitar é que a humanidade dessas populações seja rotulada por um discurso de bondade suprema, em um mundo bipolarizado entre o mau, os brancos, e o bem, os negros.

\footnotetext{
${ }^{14}$ MBEMBE, As Formas Africanas de Auto-Inscrição, 2001.

${ }^{15}$ SODRÉ, Claros e Escuros: Identidade, Povo e Mídia No Brasil, p. 237-238.
} 
Nesse sentido, Mbembe não se furta de (re)contar os fatos mais sombrios sobre a escravização de africanos e a atual política de extermínio nos países daquele continente, pois, segundo ele, em ambos os casos há coparticipação de africanos nesses sistemas mordazes. Embora Mbembe afirme esse fato, o autor não deixa sombra de dúvidas de que a potencialização dessas políticas tenha sido fomentada de fora para dentro, mas se deter a esse fato seria negligenciar que o desejo humano de poder e expansão de riquezas reorganizaram as relações sociais e as disputas políticas locais. Não seria demais, portanto, afirmar que as oligarquias que comandavam cidades em determinados países africanos, antes da colonização, tenham sido aliadas do colonialismo e da escravização.

Diop e os seus seguidores, atribuem ao fenômeno da escravização uma responsabilidade única dos dominadores europeus, pois para ele, escravizar é parte do instinto humano. Contudo, escravizar por meio de justificações filosóficas e mercadológicas, constituindo uma escala mundo, somente os europeus empreenderam esse intento. Ele afirma que:

By definition, all slaves should make up the revolutionary class. One can easily imagine the state of mind of warrior or any freeman whose condition through defeat in war radically changes from one day to the next, as he becomes a slave: as in classical antiquity, prisoners of war were automatically subject to being sold. Persons of rank might be ransomed by their families, who would give in exchange a certain number of slaves. In principle, one could have a nephew serve as a substitute: a man's sister's son, in this matriarchal regime, would be given by his uncle in ransom; whence the two Wolof expressions, na djây ("may the sell", i.e., the uncle), and djar dât ("he who can buy back", i.e., the nephew). But this is where the slaves come in. In this aristocratic regime, the nobles formed the calvary of the army (the chivalry). The infantry was composed of slaves, former prisoners of war taken from outside the national territory. The Slaves of the king formed the greater part of his force and in consequence their condition was greatly improved. They were now slaves in name only ${ }^{16}$.

Mbembe negaria esta afirmação, primeiro sob a alegação de que há um aprisionamento pré-colonial (portanto anacrônico) que ainda recai no problema da justificativa de uma humanidade mais branda no relacionamento entre os africanos. Segundo, se levarmos em consideração que essa lógica seja menos predatória do que o escravismo ocidental sobre o continente africano, tendo como princípio motor o agenciamento conduzido pela raça, o modelo se manteria inalterado e o sistema escravocrata não atravessaria os oceanos, já que os reis que escravizavam seus povos a partir de outros critérios, ainda assim mantivessem um vínculo racial, que salvaguardava o

${ }^{16}$ DIOP, Precolonial Black Africa, p. 3-4. 
direito de reabsorção social daqueles que estariam submetidos, evitariam o sequestro. Mbembe completa:

De muitas formas, a colonização foi uma co-invenção. Ela tanto foi o resultado da violência ocidental, quanto do trabalho de seus auxiliares africanos em busca de lucro. Onde havia falta de colonos brancos para ocupar o território, os poderes coloniais geralmente recrutavam os negros para colonizarem seus próprios conterrâneos (congénères) em nome da nação metropolitana. Mais decisivamente, por mais "doentio" que possa parecer, o colonialismo como fenômeno mental e material exerceu uma forte sedução sobre os africanos. Esta atração foi tanto material, como moral e intelectual. Possibilidades ostensivas de mobilidade ascendente foram prometidas pelo sistema colonial. Se tais promessas realmente foram cumpridas, é algo que não está em questão. Como uma fábrica de ficções refratada e infinitamente reconstituída, o colonialismo gerou mútuas utopias e alucinações partilhadas pelos colonizadores e pelos colonizados ${ }^{17}$.

Os desdobramentos que se tem a partir daí se observa num processo de dupla inscrição, onde os horizontes são perturbadores para colonizadores e colonizados. Cada porção de continente fora escravizado de um modo e por nações europeias distintas, reagindo e negociando de modos particulares, não havendo singularização nas estratégias de obtenção de lucros e/ou para driblar e resistir a esse sistema. Por esse motivo, tornamos a recorrer Mbembe para advertir que o escravismo ou a materialização de uma ordem sistêmica racista não triunfou sobre os negros, mas, sim, (re)organiza um campo de tensões que são redimensionadas em cada limite de produção de resistência.

Por esse motivo, para Mbembe, é sumamente importante compreender as transformações culturais ocorridas em um mundo cada vez mais conectado pelas novas tecnologias. As identidades estão em contínua transformações, na verdade sempre estiveram, mas desta vez o mundo virtual possibilita que haja maiores trocas, em uma dinâmica avassaladora que estiola a velha noção de um continente africano unificado. Segundo o autor essa seria uma visão romantizada.

$\mathrm{Na}$ verdade, não importa que definição se dê a tal noção: a unidade racial africana sempre foi um mito. Este mito atualmente está implodindo diante do impacto de fatores externos e internos conectados com as formas pelas quais as sociedades africanas estão ligadas a fluxos culturais globais ${ }^{18}$.

\footnotetext{
${ }^{17}$ MBEMBE, As Formas Africanas de Auto-Inscrição, p. 190.

${ }^{18}$ Ibidem, p. 192.
} 
As críticas não param por aí, entretanto, não constituem escopo do nosso trabalho, avançar em mais frentes que venham a trazer elementos para debates mais extensos. Essa seção foi sistematizada a fim de apresentar as críticas feitas em torno do trabalho de Cheikh Anta Diop e seus sucessores. Desse modo, e para a última possibilidade de crítica feita por aqui, trazemos um fragmento de Frantz Fanon como compreensão daquele que pensa o devir liberado, ou seja, a teoria anti-colonialista que não se faz valer do revanchismo e ressentimento, ainda que se trabalhe a partir dos traumas psicológicos sofridos pela colonização ("Pele Negra, Máscaras Brancas”), da violência física e psíquica em que se assenta a geografia do colonizado (“Os Condenados da Terra”) e sobre as possíveis organizações políticas - com seus momentos de violência inevitáveis necessárias para o processo de libertação da força colonial ("Em Defesa da Revolução Africana”).

Não quero, acima de tudo, ser mal compreendido. Estou convencido de que há grande interesse em entrar em contato com uma literatura ou uma arquitetura do século III a.C. Ficaríamos muito felizes em saber que existe uma correspondência entre tal filósofo preto e Platão. Mas não vemos, absolutamente, em que este fato poderia mudar a situação dos meninos de oito anos que trabalham nas plantações de cana da Martinica ou de Guadalupe. Não se deve tentar fixar o homem, pois o seu destino é ser solto. A densidade da história não determina nenhum de meus atos. Eu sou meu próprio fundamento. É superando o dado histórico, instrumental, que introduzo o ciclo de minha liberdade. A desgraça do homem de cor é ter sido escravizado. A desgraça e a desumanidade do branco consistem em ter matado o homem em algum lugar. Consiste, ainda hoje, em organizar racionalmente essa desumanização. Mas, eu, homem de cor, na medida em que me é possível existir absolutamente, não tenho o direito em me enquadrar em um mundo de reparações retroativas. $\mathrm{Eu}$, homem de cor, só quero uma coisa: Que o jamais o instrumento domine o homem, que cesse para sempre a servidão do homem pelo homem. Ou seja, de mim por outro. Que me seja permitido descobrir e querer e querer bem ao homem, onde quer que ele se encontre. O preto não é. Não mais que o branco ${ }^{19}$.

Portanto, essas são somente algumas possibilidades para empreender críticas a Diop e as linhas extensivas que se nutrem do pensamento advindo do senegalês. São pensamentos ancorados em pensadores que discordam da maneira em que foram apresentadas as teses, e produzem seus pontos de vista a partir de traçados epistemológicos que estão na direção oposto ao que a perspectiva afrocentrada visa empreender. Esse é um exercício contínuo no qual necessita de maior espaço para

${ }^{19}$ FANON, Pele Negra, Máscaras Brancas, p. 190-191. 
expressões mais exaustivas. Entretanto, estamos satisfeitos em ter posto as questões que pensamos serem chaves para estender para outras informações relevantes que se (re)fazem por meio da crítica.

\section{Considerações finais}

Os arcabouços filosóficos e sociológicos que organizam as nações, estejam elas em qualquer continente, se balizam através do pensamento eurocêntrico, que se auto referenda enquanto sistema excelso, axioma que se refaz no jogo de "sujeição de saberes" 20 tornados indispensáveis para sobreviver. Esse fato, no entanto, não anula a possibilidade de agenciamentos que encontram substratos importantes para a reorganização de espaços comuns de convivência, onde a miséria existencial não assente morada.

Recontar a história e trazer à tona novos elementos para a acareação crítica, a fim de apresentar alternativas ao modelo de vida predatório ensejado pelo ocidente, é tarefa que requer coragem, inclinação para pesquisas acadêmicas e incansável disputa política. Cheikh Anta Diop foi um gigantesco intelectual, incansável no combate ao racismo, não se limitou a uma área de conhecimento, seu desejo de justiça o deslocou para os mais árduos campos de batalha, tendo que confrontar com forças políticas que desacreditavam em seus projetos e / ou os rejeitava, pelo simples fato de realimentar sistemas de poder que dão força para a manutenção do racismo.

Desse modo, Cheik Anta Diop teve o inquestionável mérito de pôr em xeque alguns ordenamentos operativos que irradiava conhecimentos a partir de um único lugar. Diop foi incansável na busca de descortinar algumas contradições da filosofia e das ciências ocidentais, que ao se estabelecerem como fonte incontestável de produção de saberes, anulava a importância do que se produzia em âmbito local, em outros continentes. Não obstante, o ponto chave não seria compreender os povos africanos a partir do crivo do ocidente, mas produzir uma ciência autóctone sem tangenciar elementos ocidentais que explicasse o funcionamento de tais culturas, e nessa tarefa Diop falhou, diriam os seus críticos.

Segundo Mbembe, tanto Diop quanto os seus sucessores, esbarrariam nas transformações das relações sociais do mundo, que, na verdade, advogada para novos olhares e constante revisões do período no qual esses intelectuais haviam se debruçado para questionar a linha histórica de subdesenvolvimento do continente africano pelo europeu. Segundo ele, e tantos outros estudiosos, haveria uma tendência - a partir de Diop - em romantizar o continente africano, imobilizando suas populações no lugar da

\footnotetext{
${ }^{20}$ Sobre sujeição de saberes é importante entender que se trata da massificação de valores referendados pelos sistemas de poder, aos quais servem para a organização do lugar de dominação, estabelecendo papéis sociais a partir dos conhecimentos normalizados, criando uma norma que retorna a si mesmo, mesmo diante dos momentos de crise. Ver FOUCAULT, Em Defesa da Sociedade, 2011.
} 
passividade e da homogeneidade, quando se sabe que o continente africano é o que possui o maior número de países e a segunda maior população mundial, logo bastante diverso.

A crítica é taxativa e afirma que: "A unidade racial africana sempre foi um mito" 21. Nesse sentido, enxergam como negativa a posição de muitos pesquisadores que tentam pôr em oposição as populações do continente africano ao europeu, tendo como ponto de partida o critério racial, pois entendem que essa posição acorrentaria os negros aos guetos da diferença, inviabilizando o ingresso na universalidade da humanidade. Importante salientar que o autor não defende a ideia de que firmar a condição de ser humano tenha que se inscrever nos ditames do ocidente, ele rejeita a ideia defendida pelos pesquisadores da afrocentricidade, de polarizar e generalizadamente uma moral negativa - em relação as populações brancas ocidentais -, e positiva para os negros africanos e seus descendentes.

Essa leitura, segundo Mbembe, desprivilegia a existência de cooperações indispensáveis para a resolução de problemas pontuais que assolam a humanidade. Desse modo, a afrocentricidade como linha extensiva do legado de Cheikh Anta Diop, teria transformado de maneira negativa o que o senegalês teria deixado como possibilidade de reorganização do olhar acadêmico sobre o continente africano. A crítica de Muniz Sodré ${ }^{22}$ é encaminhada nessa mesma direção, se concentrando muito mais nos desdobramentos do pensamento de Diop do que em suas obras propriamente dita.

Portanto, apresentamos, de maneira breve, o que inviabiliza uma adesão total as alternativas que apresentam um caminho diferente do convencional. A estrada tornada convencional também não é a mais segura e inquestionável, por isso o alerta que se faz necessário é que se tenha frieza e responsabilidade na digestão dessas teses. Ler e entender as obras de Diop é sumamente recomendável, pois serve como elemento fundamental para o questionamento do paradigma hegemônico. Entretanto, é necessário não acorrentar o conhecimento. Se valer da multiplicidade de correntes filosóficas e científicas, é estender linhas conceituais que contribuirão positivamente para um fazer acadêmico substancial e honesto.

\section{Referências}

BERGSON, Henri. A Evolução Criadora. São Paulo: Editora UNESP, 2009.

DIOP, Cheikh. The African Origin of Civilization: Myth or Reality. Chicago: Lawrence Hill \& Co., 1974.

DIOP, C. Precolonial Black Africa. Chicago: Lawrence Hill Books, 1987.

\footnotetext{
${ }^{21}$ MBEMBE, As Formas Africanas de Auto-Inscrição, p. 192.

22 SODRÉ, Claros e Escuros: Identidade, Povo e Mídia No Brasil, 2000.
} 
DIOP, C. A unidade Cultural da África Negra: Esferas do Patriarcado e do Matriarcado na Antiguidade Clássica. Luanda: Edições Mulemba, 2014.

FANON, F. Os Condenados da Terra. Rio de Janeiro: Civilização Brasileira, 1961.

FANON, F. Pele Negra, Máscaras Brancas. Salvador: EDUFBA, 2008.

FANON, F. Em Defesa da Revolução Africana. Lisboa: Livraria Sá da Costa Editora, 1980.

FOUCAULT, Michel. Em Defesa da Sociedade. São Paulo: Martins Fontes, 2010.

MBEMBE, Achile. As Formas Africanas de Auto-Inscrição. Estudos Afro-Asiáticos, Ano 23, no $1,2001$.

MOORE, Carlos. A Humanidade Contra si Mesma: Para uma Nova Interpretação Epistemológica do Racismo e de seu Papel Estruturante na História e no Mundo Contemporâneo. II Fórum Internacional Afro-colombiano. Bogotá, 18 de maio de 2011. Anais: 1-17.

OBENGA, Thèophile. O Egipto da Obra de Platão. In: DIOP, Babacar Mbaye; DIENG, Doudou. A Consciência Histórica Africana. Luanda: Edições Mulemba, 2014.

SODRÉ, Muniz. Claros e Escuros: Identidade, Povo e Mídia No Brasil. Petrópolis: Editora Vozes, 2000. 